\title{
Caveolin-1 mediates tumor cell migration and invasion and its regulation by $m i R-133 a$ in head and neck squamous cell carcinoma
}

\author{
NIJIRO NOHATA ${ }^{1,2}$, TOYOYUKI HANAZAWA ${ }^{2}$, NAOKO KIKKAWA ${ }^{1,2}$, MURADIL MUTALLIP ${ }^{1,2}$, \\ LISA FUJIMURA $^{3}$, HIROFUMI YOSHINO ${ }^{4}$, KAZUMORI KAWAKAMI ${ }^{4}$, TAKESHI CHIYOMARU ${ }^{4}$, \\ HIDEKI ENOKIDA ${ }^{4}$, MASAYUKI NAKAGAWA ${ }^{4}$, YOSHITAKA OKAMOTO ${ }^{2}$ and NAOHIKO SEKI ${ }^{1}$ \\ Departments of ${ }^{1}$ Functional Genomics, ${ }^{2}$ Otorhinolaryngology/Head and Neck Surgery, \\ Graduate School of Medicine, ${ }^{3}$ Biomedical Research Center, Chiba University, Chiba; ${ }^{4}$ Department of Urology, \\ Graduate School of Medical and Dental Sciences, Kagoshima University, Kagoshima, Japan
}

Received September 2, 2010; Accepted October 27, 2010

DOI: 10.3892/ijo_00000840

\begin{abstract}
MicroRNAs (miRNAs) are small non-coding RNAs of approximately 22 nucleotides that can function as oncogenes or tumor suppressors in human cancer. Downregulation of the miRNA miR-133a in many type of cancers, and a reduction of cell proliferation, migration, and invasion upon over-expression, suggests that miR-133a is a tumor suppressor. In this study, genome-wide gene expression analysis of HNSCC cells that over-express $m i R-133 a$ showed that caveolin-1 (CAVI), a multifunctional scaffolding protein, is down-regulated, a result that was confirmed by real-time PCR and Western blot analysis. A luciferase reporter assay revealed that $m i R-133 a$ is directly bound to CAVI mRNA. Cancer cell migration and invasion were significantly inhibited in HNSCC cells transfected with si-CAV1. Therefore, CAV1 functions as an oncogene in HNSCC. The identification of tumor suppressive miRNAs and their target genes could provide new insights into potential mechanism of HNSCC carcinogenesis.
\end{abstract}

\section{Introduction}

MicroRNAs (miRNAs) are small non-coding RNAs with a length of approximately 22 nucleotides. They regulate gene expression by mRNA cleavage and at the post-transcriptional level by translational suppression (1). They play important roles in various biological and metabolic processes, including development, differentiation, signal transduction, cell maintenance, and cancer $(1,2)$. Bioinformatic predictions indicate

Correspondence to: Dr Naohiko Seki, Department of Functional Genomics, Chiba University Graduate School of Medicine, 1-8-1 Inohana Chuo-ku, Chiba 260-8670, Japan

E-mail: naoseki@faculty.chiba-u.jp

Key words: miR-133a, HNSCC, caveolin-1, migration, invasion that miRNAs regulate more than $30 \%$ of the protein coding genes (3). It is estimated that approximately 1,000 miRNAs exist in the vertebrate genome. So far, 1048 human miRNAs are registered at miRBase release 16.0 (http://microrna.sanger. ac.uk/).

An important role for miRNAs in the development of cancer has emerged in recent years (4). They are aberrantly expressed in many human cancers, and may function as oncogenes and tumor suppressors. A growing body of evidence indicates that unique miRNA expression profiles associated with particular cancers could serve as useful biomarkers for disease diagnosis and prognosis (5-7). Studies have been carried out for the purpose of identifying specific miRNA alterations in various cancers, including head and neck squamous cell carcinoma (HNSCC) (8-10).

Down-regulated miRNAs, including $m i R-133 a$, have been identified in bladder cancer and esophageal squamous cell carcinoma (ESCC) $(11,12)$. Down-regulation of $m i R-133 a$ has also been reported in HNSCC, and oral and colorectal cancers $(7,13,14)$. The finding that over-expression of $m i R-133 a$ reduces cell proliferation, migration and invasion suggested that $m i R-133 a$ is a tumor suppressor $(12,15)$. In this study, a screen for $m i R-133 a$ target genes was performed using genome-wide expression analysis on HNSCC cell lines (HSC3 and SAS) transfected with miR-133a. Among the downregulated genes, caveolin-1 (CAVI) contained predicted binding sites for $m i R-133 a$.

Caveolins are a class of oligomeric structural proteins that are both necessary and sufficient for caveolae formation. Caveolae are 50- to $100-\mathrm{nm} \omega$-shaped invaginations of the plasma membrane that function as regulators of signal transduction. CAV1 regulates multiple cancer-associated processes including cellular transformation, tumor growth, cell migration and metastasis, cell death and survival, multidrug resistance and angiogenesis $(16,17)$.

A luciferase reporter assay was used to determine if $C A V 1$ actually has $m i R-133 a$ target sites. The functional significance of CAV1 in HNSCC was also investigated using a loss-offunction assay. This is the first report that oncogenic CAV1 is 
directly controlled by tumor suppressive microRNA, $m i R-133 a$, in HNSCC.

\section{Materials and methods}

Clinical HNSCC specimens and HNSCC cell culture. Twentyfive pairs of primary HNSCC (oral cavity 11, larynx 3, oropharynx 5, and hypopharynx 6) and corresponding normal epithelial samples were obtained from patients in Chiba University Hospital (Chiba, Japan) from 2007 to 2009. All tissue specimens were obtained from patients undergoing surgical treatment. Normal tissues were obtained far from the center of the cancer in surgical specimens. No cancer cells were detected in neighboring formalin-fixed paraffin-embedded tissues. Written consent of tissue donation for research purposes was obtained from each patient before tissue collection. The protocol was approved by the Institutional Review Board of Chiba University. The specimens were immersed in RNAlater (Qiagen, Valencia, CA, USA) and stored at $-20^{\circ} \mathrm{C}$ until RNA was extracted. Human HNSCC cell lines (HSC3; derived from lymph node metastasis of tongue squamous cell carcinoma and SAS; derived from primary lesion of tongue squamous cell carcinoma) were provided by the American Type Culture Collection (ATCC, Manassas, VA, USA). Both cell lines were grown in Dulbecco's modified Eagle's medium/ nutrient mixture F-12 Ham (DMEM/F-12) supplemented with $10 \%$ fetal bovine serum in a humidified atmosphere containing $5 \% \mathrm{CO}_{2}$ at $37^{\circ} \mathrm{C}$.

RNA isolation. Total RNA was isolated using TRIzol reagent (Invitrogen, Carlsbad, CA, USA) according to the manufacturer's protocol. RNA concentrations were determined spectrophotometrically, and molecule integrity was checked by gel electrophoresis. RNA quality was confirmed using an Agilent 2100 Bioanalyzer (Agilent Technologies, Santa Clara, CA, USA).

Mature miRNA transfection and small interfering RNA treatment. Mature miRNA molecules, Pre-miR ${ }^{\mathrm{TM}}$ miRNA precursors (hsa-miR-133a; P/N: AM17100 and negative control miRNA; P/N: AM17111), small interfering RNA, Silencer ${ }^{\circledR}$ Select siRNA; si-CAV1 (P/N: s2446 and s2448) (Applied Biosystems, Foster City, CA, USA) and negative control siRNA (D-001810-10; Thermo Fisher Scientific, Waltham, MA, USA) were incubated with Opti-MEM (Invitrogen) and Lipofectamine $^{\mathrm{TM}}$ RNAiMax reagent (Invitrogen) as described previously (11). Transfection efficiency of Pre-miR in cell lines was confirmed based on down-regulation of PTK 9 mRNA following transfection with $m i R-1$ (as recommended by the manufacturer).

Cell proliferation, migration and invasion assays. Cells were transfected with $10 \mathrm{nM}$ siRNA by reverse transfection and plated into 96 -well plates at $3 \times 10^{3}$ cells per well. After $72 \mathrm{~h}$, cell proliferation was determined by the XTT assay, using the Cell Proliferation Kit II (Roche Molecular Biochemicals, Mannheim, Germany) (12,18). Triplicate wells were measured for cell viability in each treatment group.

Cell migration activity was evaluated using a woundhealing assay. Cells were plated in 6-well dishes, and the cell monolayer was scraped using a micropipette tip. The initial gap length $(0 \mathrm{~h})$ and the residual gap length, $24 \mathrm{~h}$ after wounding were calculated from photomicrographs (15).

A cell invasion assay was carried out using modified Boyden Chambers containing transwell-precoated matrigel membrane filter inserts with $8-\mu \mathrm{m}$ pores in 24 -well tissue culture plates (BD Biosciences, Bedford, MA, USA) (15). All experiments were performed in triplicate.

Target gene search for miR-133a. A genome-wide screen using $m i R-133 a$ transfectants was performed to identify target genes of $m i R-133 a$ in two HNSCC cell lines, HSC3 and SAS. Oligomicroarray Human 44K (Agilent Technologies) was used for expression profiling in the transfectants in comparison with a miRNA-negative-control transfectant $(12,15,18)$. Hybridization and wash steps were performed as previously described (19). The arrays were scanned using a Packard GSI Lumonics ScanArray 4000 (Perkin-Elmer, Boston, MA, USA). The data were analyzed by means of DNASIS array software (Hitachi Software Engineering, Tokyo, Japan), which converted the signal intensity for each spot into text format. The Log 2 ratios of the median subtracted background intensity were analyzed. Data from each microarray study were normalized by a global normalization method (19).

Predicted target genes and their target miRNA binding site seed regions were investigated using TargetScan (release 5.1, http://www.targetscan.org/). The sequences of the predicted mature miRNAs were confirmed using miRBase (release 16.0, http://microrna.sanger.ac.uk/).

Real-time quantitative RT-PCR. First-strand cDNA was synthesized from $1 \mu \mathrm{g}$ total RNA using High Capacity cDNA Reverse Transcription Kit (Applied Biosystems). Gene-specific PCR products were assayed continuously using a 7900-HT Real-Time PCR System according to the manufacturer's protocol. The initial PCR step consisted of a 10-min hold at $95^{\circ} \mathrm{C}$, followed by 40 cycles of a 15 -sec denaturation at $95^{\circ} \mathrm{C}$ and a 1 -min annealing/extension at $63^{\circ} \mathrm{C}$. TaqMan ${ }^{\circledR}$ probes and primers for $C A V 1$ (P/N: Hs00971716_m1) and the GAPDH (A/N: NM_002046) internal control were obtained from Applied Biosystems (Assay-On-Demand Gene Expression Products). The expression levels of $m i R-133 a$ (P/N: 002246) were analyzed by TaqMan quantitative real-time PCR (TaqMan MicroRNA Assay; Applied Biosystems) and normalized to RNU48 (A/N: X96648). All reactions were performed in triplicate, and included negative control reactions that lacked cDNA.

Immunoblotting. Cells were harvested $72 \mathrm{~h}$ after transfection and lystaes were prepared. Protein lysate $(50 \mu \mathrm{g})$ was separated by NuPAGE on a $4-12 \%$ bis-tris gel (Invitrogen) and transferred to PVDF membranes. Immunoblotting was performed with diluted $(1: 100)$ monoclonal CAV1 antibody (ab17052, Abcam, Cambridge, UK), with B-actin antibody (sc-1615; Santa Cruz Biotechnology, Santa Cruz, CA, USA) used as an internal control. The membrane was washed and incubated with goat anti-mouse $\operatorname{IgG}(\mathrm{H}+\mathrm{L})$-HRP conjugate (Bio-Rad, Hercules, CA, USA). Specific complexes were visualized by echochemiluminescence (GE Healthcare BioSciences, Princeton, NJ, USA). 
Table I. Top 25 genes down-regulated less than -2.00-fold in miR-133a transfectants.

\begin{tabular}{|c|c|c|c|c|c|c|c|}
\hline \multirow[b]{2}{*}{ No. } & \multirow[b]{2}{*}{$\begin{array}{c}\text { Entrez } \\
\text { gene ID }\end{array}$} & \multirow[b]{2}{*}{ Symbol } & \multirow[b]{2}{*}{ Gene name } & \multicolumn{3}{|c|}{$\log 2$ ratio } & \multirow[b]{2}{*}{$\begin{array}{l}\text { Target } \\
\text { sites }\end{array}$} \\
\hline & & & & SAS & HSC3 & Average & \\
\hline 1 & 63827 & BCAN & Brevican & -3.80 & -3.96 & -3.88 & - \\
\hline 2 & 10186 & LHFP & Lipoma HMGIC fusion partner & -2.97 & -4.53 & -3.75 & + \\
\hline 3 & 857 & CAV1 & Caveolin 1 , caveolae protein, $22 \mathrm{kDa}$ & -2.59 & -4.85 & -3.72 & + \\
\hline 4 & 7431 & VIM & Vimentin & -3.58 & -3.47 & -3.53 & - \\
\hline 5 & 10970 & CKAP4 & Cytoskeleton-associated protein 4 & -2.49 & -4.46 & -3.48 & + \\
\hline 6 & 1070 & CETN3 & $\begin{array}{l}\text { Centrin, EF-hand protein, } 3 \text { (CDC31 } \\
\text { homolog, yeast) }\end{array}$ & -2.48 & -4.33 & -3.41 & + \\
\hline 7 & 1295 & COL8A1 & Collagen, type VIII, $\alpha 1$ & -3.40 & 3.38 & -3.39 & - \\
\hline 8 & 359821 & MRPL42P5 & $\begin{array}{l}\text { Mitochondrial ribosomal protein L42 } \\
\text { pseudogene } 5\end{array}$ & -3.40 & -3.29 & -3.35 & - \\
\hline 9 & 55425 & KIAA1704 & KIAA1704 & -2.54 & -4.09 & -3.31 & - \\
\hline 10 & 121457 & IKIP & IKBKB interacting protein & -3.05 & -3.56 & -3.30 & - \\
\hline 11 & 7168 & TPM1 & Tropomyosin $1(\alpha)$ & -3.28 & -3.28 & -3.28 & - \\
\hline 12 & 23621 & BACE1 & $ß$-site APP-cleaving enzyme 1 & -3.35 & -2.88 & -3.11 & + \\
\hline 13 & 5923 & RASGRF1 & $\begin{array}{l}\text { Ras protein-specific guanine } \\
\text { nucleotide-releasing factor } 1\end{array}$ & -2.49 & -3.67 & -3.08 & - \\
\hline 14 & 79026 & AHNAK & AHNAK nucleoprotein & -3.33 & -2.83 & -3.08 & - \\
\hline 15 & 8835 & SOCS2 & Suppressor of cytokine signaling 2 & -1.95 & -4.18 & -3.07 & - \\
\hline 16 & 255758 & MGC33212 & Tctex 1 domain containing 2 & -3.00 & -3.10 & -3.05 & - \\
\hline 17 & 63920 & LOC63920 & Chromosome 5 open reading frame 54 & -1.92 & -4.07 & -3.00 & - \\
\hline 18 & 7424 & VEGFC & Vascular endothelial growth factor C & -1.84 & -4.11 & -2.97 & + \\
\hline 19 & 83879 & $\mathrm{CDCA} 7$ & Cell division cycle associated 7 & -1.42 & -4.51 & -2.96 & - \\
\hline 20 & 667 & DST & Dystonin & -1.91 & -4.01 & -2.96 & + \\
\hline 21 & 200894 & ARL13B & ADP-ribosylation factor-like 13B & -1.85 & -4.05 & -2.95 & + \\
\hline 22 & 1063 & CENPF & Centromere protein $\mathrm{F}, 350 / 400 \mathrm{ka}$ (mitosin) & -1.49 & -4.37 & -2.93 & - \\
\hline 23 & 79827 & ASAM & Adipocyte-specific adhesion molecule & -2.83 & -2.99 & -2.91 & - \\
\hline 24 & 29843 & SENP1 & SUMO1/sentrin specific peptidase 1 & -2.24 & -3.55 & -2.89 & + \\
\hline 25 & 2760 & GM2A & GM2 ganglioside activator & -3.00 & -2.78 & -2.89 & - \\
\hline
\end{tabular}

Plasmid construction and dual-luciferase assay. miR-133a target sequences were inserted between the XhoI and PmeI restriction sites in the 3'UTR of the hRluc gene in the psiCHECK-2 vector (Promega, Madison, WI, USA). The amplified fragment was cloned into the psiCHECK-2 vector and confirmed by sequencing using the following primers: 5'-ACCGAGTTCGTGAAGGTGAA-3' and 5'-CAAACCCT AACCACCGCTTA-3'. SAS cells were then transfected with 5 ng vector, $10 \mathrm{nM}$ mature miRNA molecules, Pre-miRNA ${ }^{\mathrm{TM}}$ $m i R-133 a$ (Applied Biosystems), and $1 \mu 1$ Lipofectamine 2000 (Invitrogen) in $100 \mu 1$ Opti-MEM $^{\mathrm{TM}}$. Firefly and Renilla luciferase activities in cell lysates were determined using a dual-luciferase assay system (Promega). Normalized data were calculated as the quotient of Renilla/firefly luciferase activities.

Statistical analysis. The relationships between two groups and the numerical values obtained by real-time RT-PCR were analyzed using the non-parametric Mann-Whitney's U test or the paired t-test. The relationship among three variables and numerical values was analyzed using the Bonferroni-adjusted Mann-Whitney's U test; a non-adjusted statistical level of significance of $\mathrm{P}<0.05$ corresponded to a Bonferroni-adjusted level of $\mathrm{P}<0.0167$. All analyses were performed using Expert StatView (version 4, SAS Institute Inc., Cary, NC, USA).

\section{Results}

Identification of miR-133a target genes by genome-wide expression analysis. To investigate the molecular basis of candidate targets of $m i R-133 a$ in HNSCC cells, we examined the effect of $m i R-133 a$ on protein-coding genes. Mature $m i R-133 a$ was transiently transfected into HSC3 and SAS cells, with negative-miRNA transfection used as a control. Comprehensive gene expression analysis (see Materials and methods) clearly showed changes in gene expression patterns between $m i R-133 a$ and negative-control transfectants. To identify candidate $m i R-133 a$ target genes, a cut-off of values less than -2.00-fold was applied to the array data. This filtering resulted in the identification of 164 genes that were significantly down-regulated upon $m i R-133 a$ transfection both HSC3 and SAS cells (top 25 genes were shown; Table I). Entries from the microarray data were approved by the Gene Expression 
A

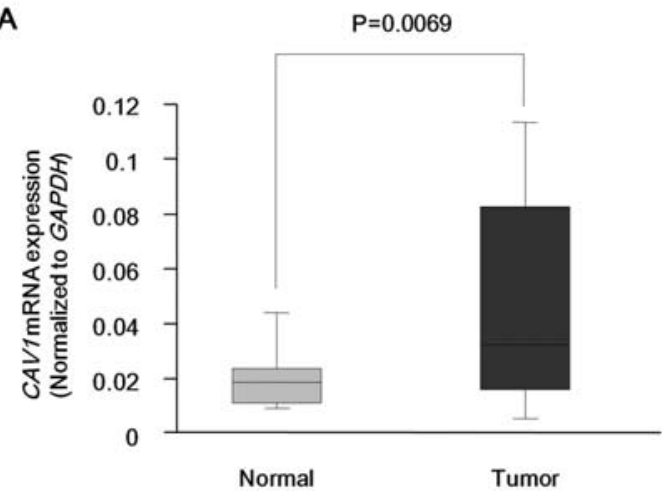

C

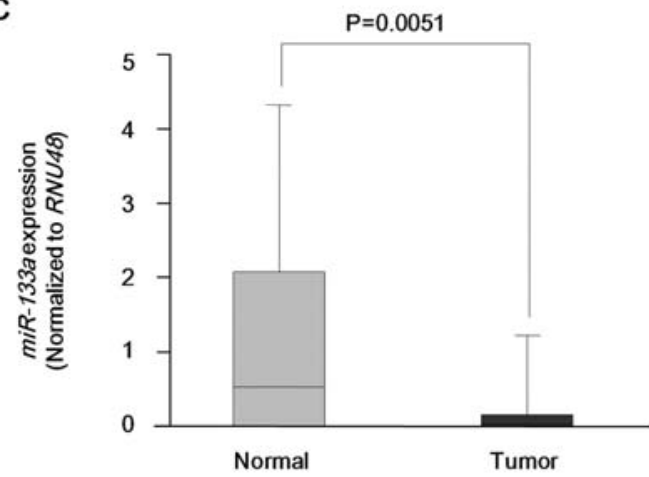

B

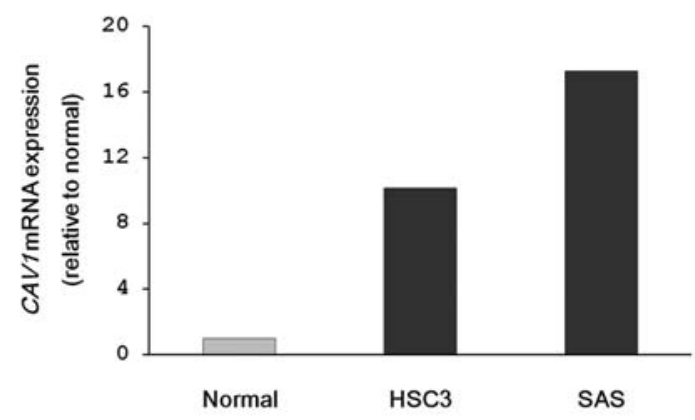

Figure 1. CAV1 mRNA expression levels from clinical specimens and HNSCC cell lines. miR-133a expression levels of clinical specimens. (A) CAV1 mRNA expression of tumor tissues and normal adjacent tissues in 25 clinical HNSCC specimens. (B) CAV1 expression in two HNSCC cell lines (HSC3 and SAS) was evaluated by real-time RT-PCR. The expression level of normal adjacent tissues was used as a reference. (C) miR-133a expression of normal adjacent tissues and tumor tissues in 25 clinical specimens of HNSCC.

Table II. Clinical features of HNSCC patients.

\begin{tabular}{rllllllll}
\hline No. & Gender & Age & Location & Differentiation & T & N & M & Stage \\
\hline 1 & Male & 60 & Oral & Well & 2 & 0 & 0 & II \\
2 & Male & 60 & Oral & Moderate & $4 \mathrm{a}$ & $2 \mathrm{c}$ & 0 & IV A \\
3 & Male & 66 & Oral & Moderate & 2 & 0 & 0 & II \\
4 & Female & 73 & Oral & Well & 1 & 0 & 0 & I \\
5 & Male & 64 & Oral & Well & 1 & 0 & 0 & I \\
6 & Male & 66 & Oral & Well & 3 & 0 & 0 & III \\
7 & Male & 58 & Oral & Moderate & 1 & 0 & 0 & I \\
8 & Male & 65 & Oral & Moderate & $4 \mathrm{a}$ & 1 & 0 & IV A \\
9 & Male & 73 & Oral & Poor & 3 & 1 & 0 & III \\
10 & Female & 38 & Oral & Well & 2 & $2 \mathrm{~b}$ & 0 & IV A \\
11 & Male & 67 & Oral & Moderate & $4 \mathrm{a}$ & $2 \mathrm{c}$ & 0 & IV A \\
12 & Male & 66 & Larynx & Well & $4 \mathrm{a}$ & 0 & 0 & IV \\
13 & Male & 69 & Larynx & Well & 3 & 0 & 0 & III \\
14 & Male & 57 & Larynx & Moderate & $4 \mathrm{a}$ & 0 & 0 & III \\
15 & Male & 64 & Oropharynx & Poor & 3 & $2 \mathrm{c}$ & 0 & IV A \\
16 & Male & 77 & Oropharynx & Moderate & $4 \mathrm{~b}$ & $2 \mathrm{~b}$ & 0 & IV B \\
17 & Male & 76 & Oropharynx & Poor & 2 & 0 & 0 & II \\
18 & Male & 52 & Oropharynx & Moderate & 3 & $2 \mathrm{a}$ & 0 & IV A \\
19 & Female & 65 & Oropharynx & Well & $4 \mathrm{a}$ & $2 \mathrm{~b}$ & 0 & IV A \\
20 & Female & 65 & Hypopharynx & Well & $4 \mathrm{a}$ & 0 & 0 & IV A \\
21 & Male & 68 & Hypopharynx & Poor & $4 \mathrm{a}$ & 1 & 0 & IV A \\
22 & Male & 68 & Hypopharynx & Moderate & $4 \mathrm{a}$ & 1 & 0 & IV A \\
23 & Male & 61 & Hypopharynx & Moderate & $4 \mathrm{a}$ & $2 \mathrm{c}$ & 0 & IV A \\
24 & Male & 66 & Hypopharynx & Moderate & 2 & $2 \mathrm{c}$ & 0 & IV A \\
25 & Female & 74 & Hypopharynx & Well & $4 \mathrm{a}$ & 0 & 0 & IV A \\
\hline
\end{tabular}



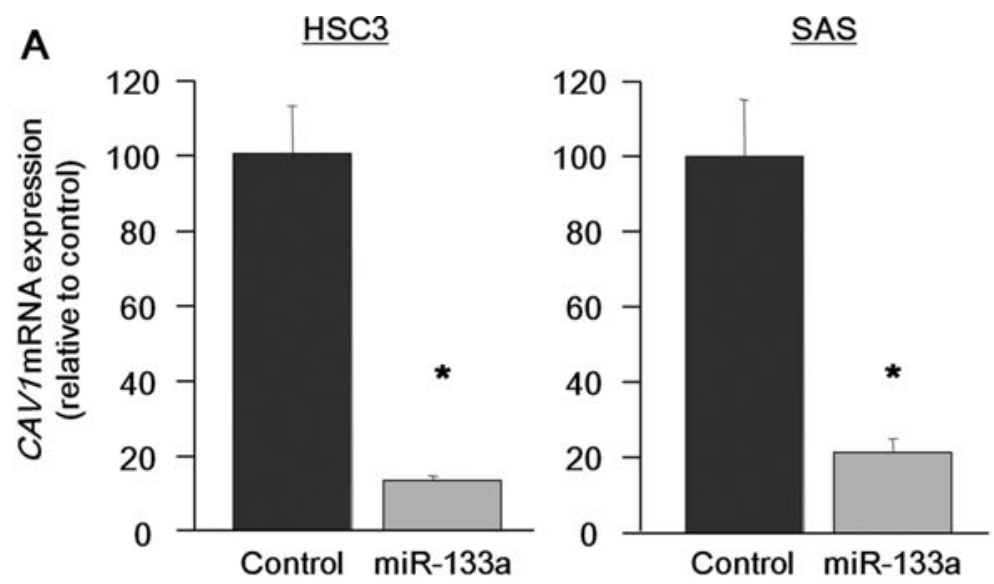

B
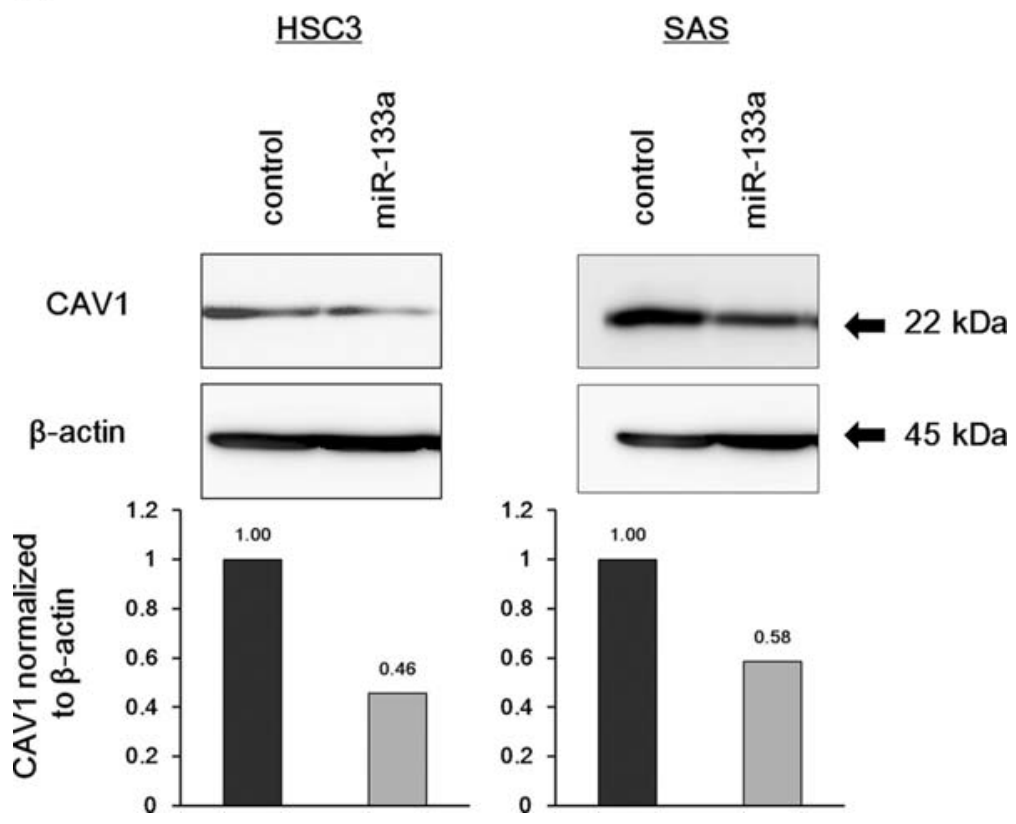

Figure 2. Regulation of CAV1 expression in miR-133a transfectants. (A) CAV1 mRNA expression was repressed in $m i R-133 a$ transfectants. ${ }^{*} \mathrm{P}<0.05$. (B) The protein expression level of CAV1 was also repressed in $m i R-133 a$ transfectants.

Omnibus (GEO), and were assigned the GEO accession number GSE20028.

The 3'UTR regions of these down-regulated genes were examined for $m i R-133 a$ target sites using the TargetScan database. Of the top 25 putative gene targets, 9 genes contained $m i R-133 a$ target sites.

CAVI mRNA and miR-133a expression in HNSCC clinical specimens. The expression level of CAVI mRNA was upregulated in clinical HNSCC specimen compared with adjacent normal tissues (Fig. 1A). CAV1 mRNA expressions in HNSCC cell lines were also over-expressed relative to normal epithelia (Fig. 1B). Conversely, miR-133a was down-regulated in tumor tissues (Fig. 1C). Characteristic data of 25 HNSCC patients are described in Table II.

CAVI as a target of post-transcriptional repression by $m i R$ 133a. CAVI was the third-ranked candidate gene in the genome-wide gene expression analysis. We focused on $C A V 1$, not first- or second-ranked genes, because the latter were not reported in association with HNSCC.

The expression level of CAV1 mRNA was significantly decreased in the two HNSCC cell lines (HSC3 and SAS) transfected with $m i R-133 a$ (Fig. 2A). The protein expression level was also markedly reduced in $m i R-133 a$ transfectants (Fig. 2B). SAS cells were used to determine the effect of $m i R-133 a$ suppression on $C A V 1$ expression. The TargetScan database identified two putative target sites in the 3'UTR of CAVI (Fig. 3, upper). A luciferase reporter assay confirmed the 3'UTR of CAVI as the actual target of $m i R-133 a$. Luciferase activity was significantly decreased in two $m i R-133 a$ target sites (position 735-741 and 888-894 in 3'UTR of CAVI) (Fig. 3, lower).

Effect of CAVI silencing on cell proliferation, migration and invasion activity in HNSCC cell lines. A loss-of-function assay using siRNA analysis was performed to examine the oncogenic function of CAV1 in the presence of miR-133a. We determined 


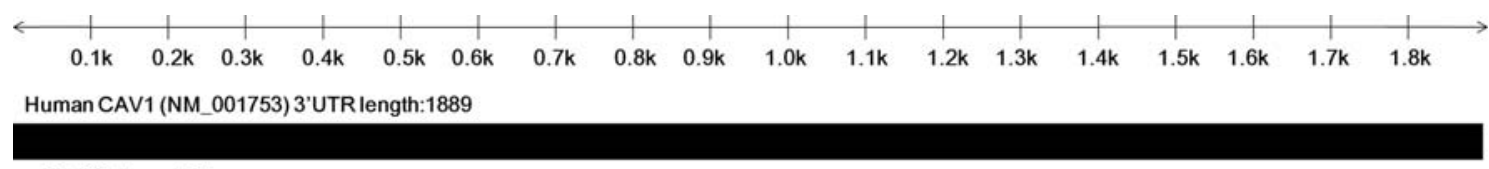

miR-133a target sites
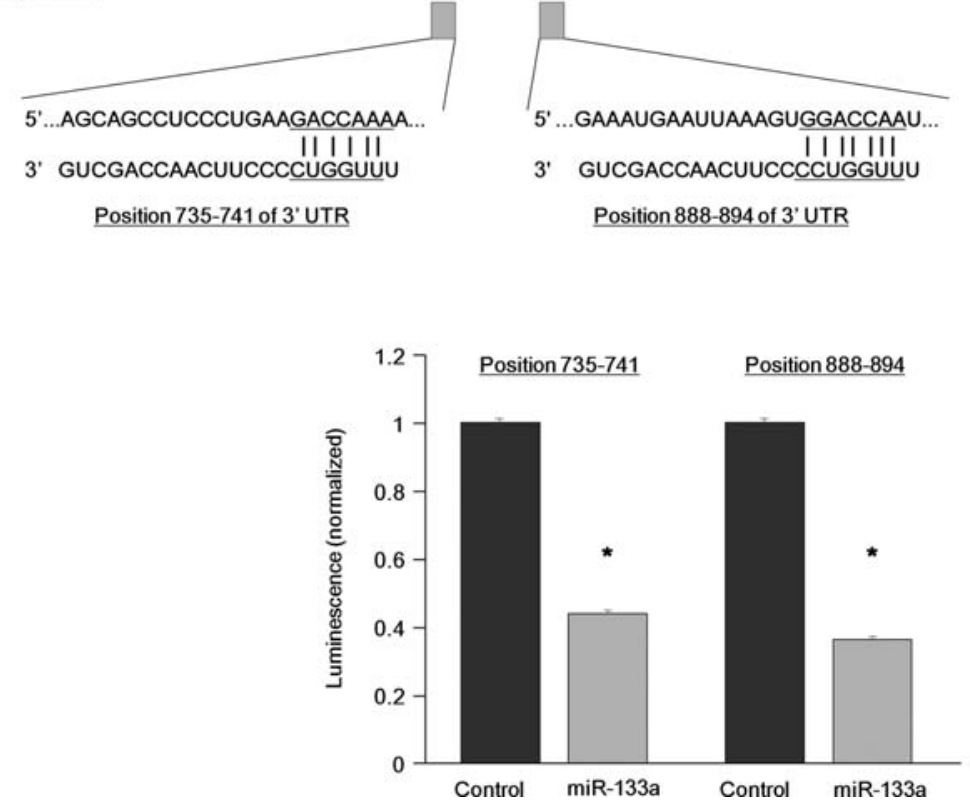

Figure 3. Putative target sites in the CAVI 3'UTR were identified with the TargetScan database: two target sites for miR-133a. The Renilla luciferase values were normalized against firefly luciferase values. ${ }^{*} \mathrm{P}<0.05$.

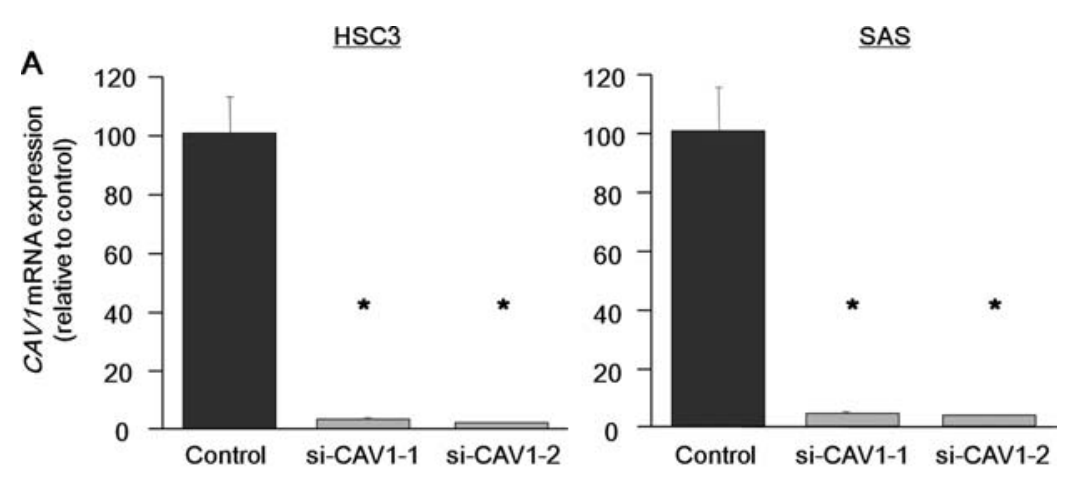

B

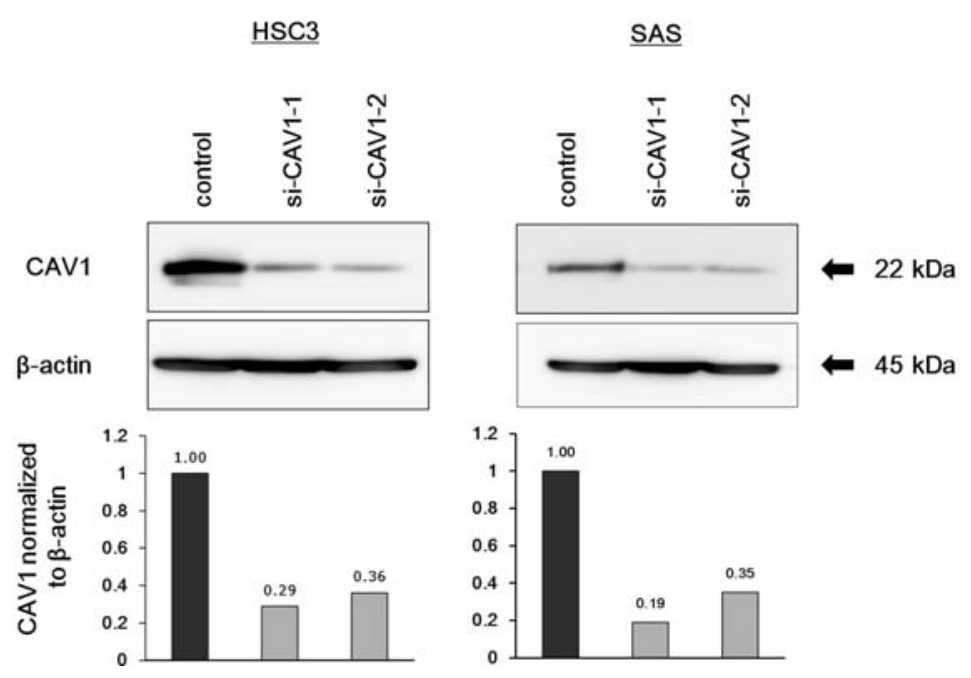

Figure 4. Effect of CAV1 knockdown on HNSCC cells. (A) RT-PCR revealed that CAV1 mRNA was markedly repressed in si-CAV1 transfectants compared with the controls. "P<0.0001. (B) Western blotting revealed that CAV1 protein was also decreased in si-CAV1 transfectants compared with the controls. 


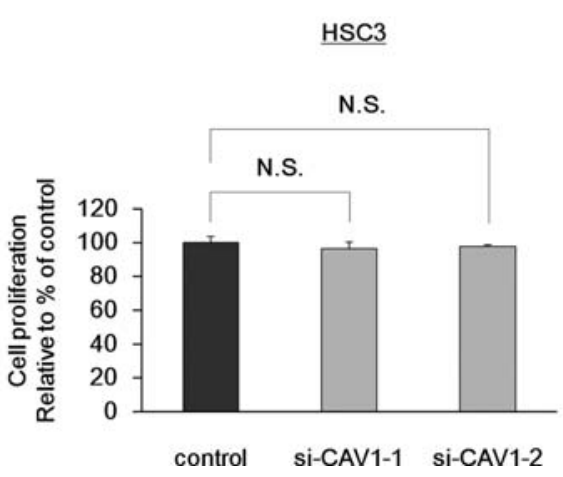

B

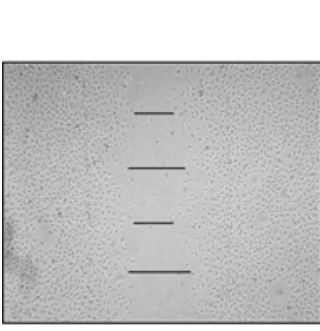

control

C

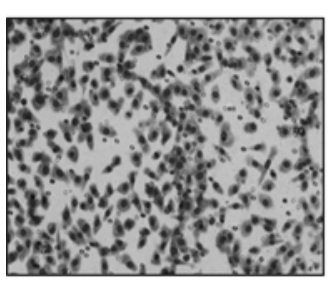

control

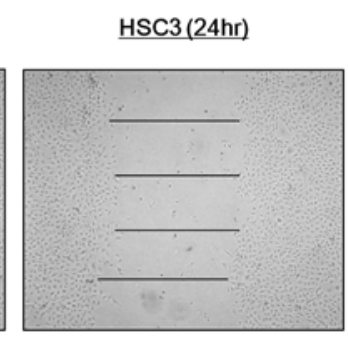

si-CAV1-1

HSC3 (24hr)

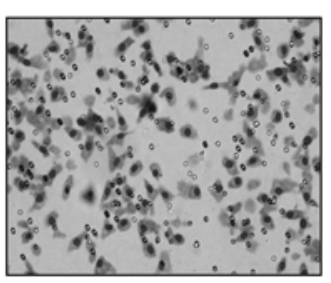

si-CAV1-1
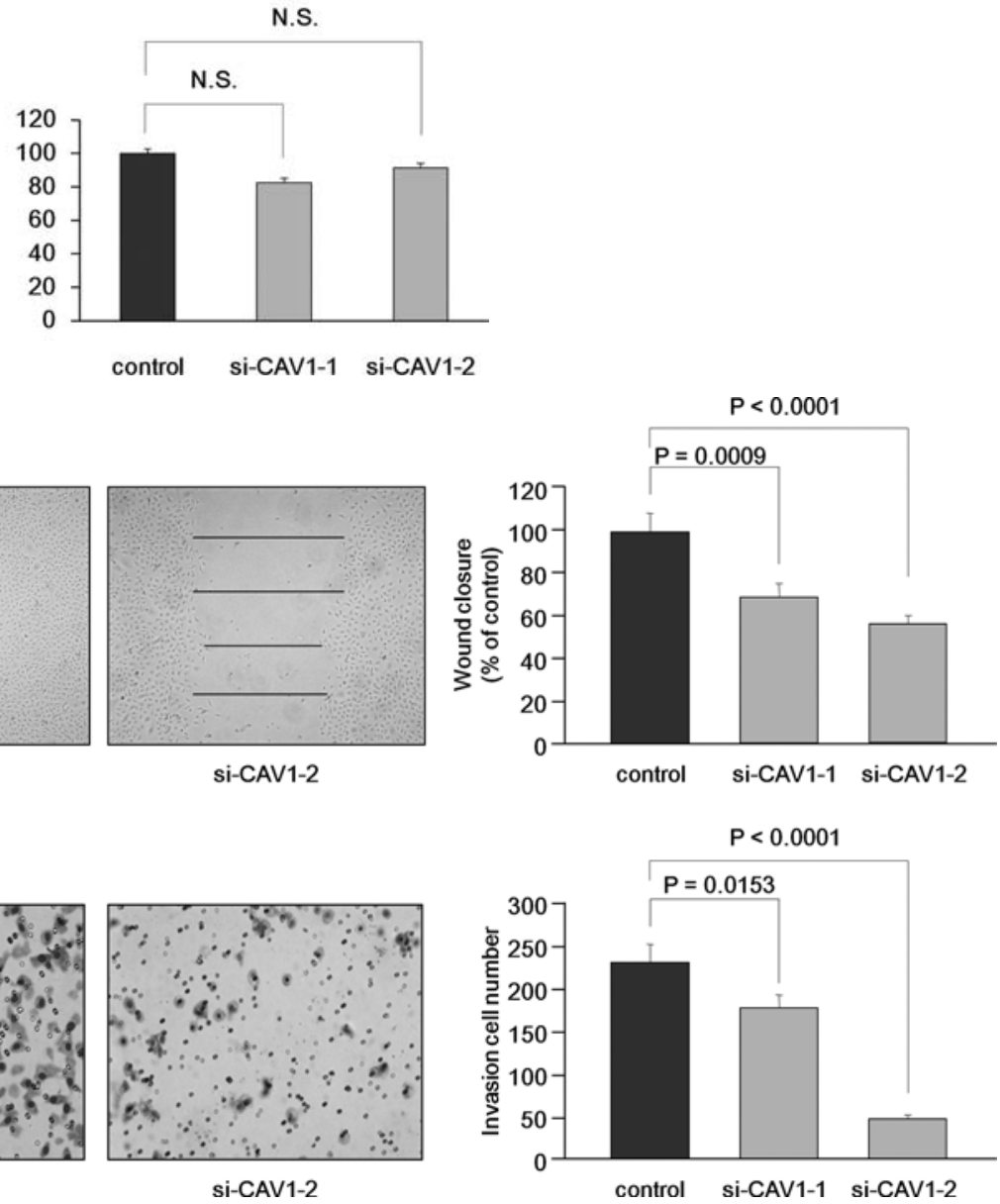

Figure 5. Loss-of-function studies using si-CAV1 transfected HNSCC cell lines. (A) Cell growth as revealed by the XTT assay; (B) Cell migration activity (wound healing assay); (C) Cell invasion activity (matrigel invasion assay) in HSC-3 transfected with si-CAV1.

whether si-CAV1 reduced both mRNA and protein expression levels of si-CAV1 transfectants in HNSCC cell lines, HSC3 and SAS. CAV1 mRNA and protein were reduced following a 72-h transfection with si-CAV1 (Fig. 4). The XTT assay revealed no significant cell growth inhibition in the si-CAV1 transfectants compared with siRNA control transfectants (Fig. 5A). The wound healing assay demonstrated that cell migration was inhibited by si-CAV1 (\% of wound closure; control: $100.0 \pm 8.1$, si-CAV1-1: $68.4 \pm 4.1$, si-CAV1-2: $59.7 \pm 5.9$, Fig. $5 \mathrm{~B}$ ), and the matrigel invasion assay showed that the number of invading cells was significantly decreased in si-CAV1 transfectants (invading cell numbers; control: 230.3 \pm 20.7 , si-CAV1-1: 176.2 \pm 15.4 , si-CAV1-2: 47.1 \pm 4.9 , Fig. 5C).

\section{Discussion}

Aberrant expression of miRNAs has been associated with the development of various cancers. To date, studies have been carried out for the purpose of identifying specific miRNA alterations in various cancers, including HNSCC (8-10). Recently, we reported several down-regulated miRNAs have been found in the expression signatures of bladder cancer and ESCC $(11,12)$. Expression studies revealed a reduction in $m i R-133 a$ levels in many types of cancers $(7,11-14,20-22)$. Consistent with these earlier studies, we found significant inhibition of cell growth, migration and invasion in ESCC and bladder cancer cell lines transfected with $m i R-133 a(12,15)$. These results strongly suggest that $m i R-133 a$ functions as a tumor suppressor. Consequently, we focused on $m i R-133 a$ and continued the analysis of the molecular mechanism of $m i R-133 a$ and HNSCC oncogenesis.

A new class of regulatory molecules known as miRNAs is redefining our understanding of the molecular pathways associated with carcinogenesis. Bioinformatic predictions indicate that miRNAs regulate more than $30 \%$ of the protein coding genes (3). We adopted a method of genome-wide gene expression analysis using specific miRNA transfectants and searched for targets of $m i R-133 a$ in HNSCC cell lines. Using this strategy in several cancer cell lines led to the identification of tumor suppressive miRNA targets $(12,15,23)$. CAVI was significantly down-regulated by $m i R-133 a$ over-expression in HNSCC cell lines. The luciferase reporter assay revealed that $C A V 1$ contains sites targeted by $m i R-133 a$. This is the first 
report that tumor suppressive $m i R-133 a$ directly regulates $C A V 1$ in cancer cells. Published articles of $m i R-133 a$ targets include $m i R-133 a$ inhibited proliferation and induced apoptosis in SCC of the tongue, and directly controlled pyruvate kinase type M2 expression (20). A search for tumor suppressive miRNA targets is important for elucidation of the molecular network of HNSCC progression, to which our expression signature of $m i R-133 a$ target analysis will contribute.

Caveolins are a basic constituent of $\omega$-shaped cell membrane microdomains called caveolae. Several heterogeneous functions are attributed to caveolae and their proteins, including vesicular transport and cholesterol homeostasis $(17,24)$. A scaffolding amino acid sequence identified in CAV1 allows this protein to interact with signaling molecules such as epidermal growth factor receptor, G-proteins, c-Src-like kinases, HA-Ras, protein kinase $\mathrm{C}$, endothelial nitric-oxide synthase, and integrin $(16,25-27)$. In fact, in several types of cancer cells, CAV1 has been associated and/or co-localized with epidermal growth factor receptor (EGFR) and modulate EGFR signaling $(28,29)$. In A549 lung cancer cells, EGFR and CAV1 co-localize in the cell membrane, where CAV1 may have a role in carcinogenesis via EGFR activation, transport to its perinuclear location, and activation maintenance $(30,31)$.

Over-expression of CAV1 has been reported in nasopharyngeal cancer, ESCC, urological cancer, prostate cancer and gliomas. Up-regulation of CAV1 is associated with more aggressive behavior, increased recurrence rate and poorer prognosis (32-36). Increased CAV1 expression has recently been reported in multidrug-resistant neoplastic cells, suggesting its specific role in the acquisition and maintenance of this phenotype $(37,38)$. In this study, a loss-of-function study using si-CAV1 in HNSCC cell lines revealed that CAV1 mediates cell migration and invasion. In contrast, CAV1 appears to be a suppressor of metastatic breast cancer when expression is inhibited $(39,40)$. In HNSCC cell lines, over-expression of CAV1 may play an inhibitory role in carcinogenesis and lung metastasis through regulation of integrin B1- and Src-mediated cell-cell and cell-matrix interactions (41). CAV1 expression has been studied in several cancers, in which expression patterns were either reduced, up-regulated or unchanged; therefore, its role in cancer is still debated and highly controversial $(17,24,42)$. Further analysis of the downstream signaling pathways of CAV1 in different cancer cell types is needed to solve these contradictions.

Epithelial to mesenchymal transitions (EMT) are critical for the invasion, progression, and metastasis of epithelial carcinogenesis. Cancer cells that undergo EMT, acquire various types of malignant ability, such as invasion and metastasis to lymph node or distant organ $(43,44)$. However, the role of EMT in HNSCC remains unexplored. Overexpression of CAV1 during EMT showed tight regulation by focal adhesion kinase (FAK). It also demonstrated that FAKmediated CAV1 up-regulation was involved in cell adhesion and motility (44).

How CAV1 expression changes in many types of cancers is still unclear, but one possible mechanism is through regulation by miRNAs. Loss of $m i R-133 a$, an endogenous $C A V I$ inhibitor, may promote aberrant expression of CAV1 in cancer cells, including HNSCC, contributing to pathogenesis and cancer progression. Down-regulation of $m i R-133 a$ and over-expres- sion CAVI were identified in HNSCC, which suggests that this tumor suppressive miRNA and oncogenic mRNA pathway may be an important therapeutic target for human cancers.

\section{Acknowledgements}

This study was supported by the Ministry of Education, Science, Sports and Culture, Grant-in-Aid for Scientific Research (C), 21592187.

\section{References}

1. Bartel DP: MicroRNAs: genomics, biogenesis, mechanism, and function. Cell 116: 281-297, 2004.

2. Kloosterman WP and Plasterk RH: The diverse functions of microRNAs in animal development and disease. Dev Cell 11: 441-450, 2006.

3. Filipowicz W, Bhattacharyya SN and Sonenberg N: Mechanisms of post-transcriptional regulation by microRNAs: are the answers in sight? Nat Rev Genet 9: 102-114, 2008.

4. Hwang HW and Mendell JT: MicroRNAs in cell proliferation, cell death, and tumorigenesis. Br J Cancer 94: 776-780, 2006

5. Lu J, Getz G, Miska EA, Alvarez-Saavedra E, Lamb J, Peck D, Sweet-Cordero A, Ebert BL, Mak RH, Ferrando AA, Downing JR, Jacks T, Horvitz HR and Golub TR: MicroRNA expression profiles classify human cancers. Nature 435: 834-838, 2005.

6. Calin GA and Croce CM: MicroRNA signatures in human cancers. Nat Rev Cancer 6: 857-866, 2006.

7. Childs G, Fazzari M, Kung G, Kawachi N, Brandwein-Gensler M, McLemore M, Chen Q, Burk RD, Smith RV, Prystowsky MB, Belbin TJ and Schlecht NF: Low-level expression of microRNAs let-7d and miR-205 are prognostic markers of head and neck squamous cell carcinoma. Am J Pathol 174: 736-745, 2009.

8. Liu X, Chen Z, Yu J, Xia J and Zhou X: MicroRNA profiling and head and neck cancer. Comp Funct Genomics 2009: 837514 Epub 2009, PMID: 19753298.

9. Tran N, O'Brien CJ, Clark J and Rose B: Potential role of microRNAs in head and neck tumorigenesis. Head Neck 32: 1099-1111, 2010.

10. Cho WC: MicroRNAs: potential biomarkers for cancer diagnosis, prognosis and targets for therapy. Int J Biochem Cell Biol 42: 1273-1281, 2010.

11. Ichimi T, Enokida H, Okuno Y, Kunimoto R, Chiyomaru T, Kawamoto K, Kawahara K, Toki K, Kawakami K, Nishiyama K, Tsujimoto G, Nakagawa M and Seki N: Identification of novel microRNA targets based on microRNA signatures in bladder cancer. Int J Cancer 125: 345-352, 2009.

12. Kano M, Seki N, Kikkawa N, Fujimura L, Hoshino I, Akutsu Y, Chiyomaru T, Enokida H, Nakagawa $\mathrm{M}$ and Matsubara $\mathrm{H}$ : miR-145, miR-133a and miR-133b: tumor suppressive miRNAs target FSCN1 in esophageal squamous cell carcinoma. Int J Cancer [Epub ahead of print] PMID: 20198616.

13. Wong TS, Liu XB, Wong BY, Ng RW, Yuen AP and Wei WI: Mature miR-184 as potential oncogenic microRNA of squamous cell carcinoma of tongue. Clin Cancer Res 14: 2588-2592, 2008.

14. Arndt GM, Dossey L, Cullen LM, Lai A, Druker R, Eisbacher M, Zhang C, Tran N, Fan H, Retzlaff K, Bittner A and Raponi M: Characterization of global microRNA expression reveals oncogenic potential of miR-145 in metastatic colorectal cancer. BMC Cancer 9: 374, 2009

15. Chiyomaru T, Enokida H, Tatarano S, Kawahara K, Uchida Y, Nishiyama K, Fujimura L, Kikkawa N, Seki N and Nakagawa M: miR-145 and miR-133a function as tumour suppressors and directly regulate FSCN1 expression in bladder cancer. Br J Cancer 102: 883-891, 2010.

16. Liu P, Rudick M and Anderson RG: Multiple functions of caveolin-1. J Biol Chem 277: 41295-41298, 2002.

17. Goetz JG, Lajoie P, Wiseman SM and Nabi IR: Caveolin-1 in tumor progression: the good, the bad and the ugly. Cancer Metastasis Rev 27: 715-735, 2008.

18. Kikkawa N, Hanazawa T, Fujimura L, Nohata N, Suzuki H, Chazono H, Sakurai D, Horiguchi S, Okamoto Y and Seki N: miR-489 is a tumour-suppressive miRNA target PTPN11 in hypopharyngeal squamous cell carcinoma (HSCC). Br J Cancer 103: 877-884, 2010. 
19. Sugimoto T, Seki N, Shimizu S, Kikkawa N, Tsukada J, Shimada H, Sasaki K, Hanazawa T, Okamoto Y and Hata A: The galanin signaling cascade is a candidate pathway regulating oncogenesis in human squamous cell carcinoma. Genes Chromosomes Cancer 48: 132-142, 2009.

20. Wong TS, Liu XB, Chung-Wai Ho A, Po-Wing Yuen A, Wai-Man Ng R and Ignace Wei W: Identification of pyruvate kinase type M2 as potential oncoprotein in squamous cell carcinoma of tongue through microRNA profiling. Int J Cancer 123: 251-257, 2008.

21. Rao PK, Missiaglia E, Shields L, Hyde G, Yuan B, Shepherd CJ, Shipley J and Lodish HF: Distinct roles for miR-1 and miR-133a in the proliferation and differentiation of rhabdomyosarcoma cells. FASEB J 24: 3427-3437, 2010.

22. Szafranska AE, Davison TS, John J, Cannon T, Sipos B, Maghnouj A, Labourier E and Hahn SA: MicroRNA expression alterations are linked to tumorigenesis and non-neoplastic processes in pancreatic ductal adenocarcinoma. Oncogene 26: 4442-4452, 2007.

23. Chiyomaru T, Enokida H, Kawakami K, Tatarano S, Uchida Y, Kawahara K, Nishiyama K, Seki N and Nakagawa M: Functional role of LASP1 in cell viability and its regulation by microRNAs in bladder cancer. Urol Oncol [Epub ahead of print] PMID: 20843712.

24. Carver LA and Schnitzer JE: Caveolae: mining little caves for new cancer targets. Nat Rev Cancer 3: 571-581, 2003.

25. Drab M, Verkade P, Elger M, Kasper M, Lohn M, Lauterbach B, Menne J, Lindschau C, Mende F, Luft FC, Schedl A, Haller H and Kurzchalia TV: Loss of caveolae, vascular dysfunction, and pulmonary defects in caveolin-1 gene-disrupted mice. Science 293: 2449-2452, 2001.

26. Okamoto T, Schlegel A, Scherer PE and Lisanti MP: Caveolins, a family of scaffolding proteins for organizing 'preassembled signaling complexes' at the plasma membrane. J Biol Chem 273: 5419-5422, 1998.

27. Razani B, Altschuler Y, Zhu L, Pestell RG, Mostov KE and Lisanti MP: Caveolin-1 expression is down-regulated in cells transformed by the human papilloma virus in a p53-dependent manner. Replacement of caveolin-1 expression suppresses HPVmediated cell transformation. Biochemistry 39: 13916-13924, 2000.

28. Abulrob A, Giuseppin S, Andrade MF, McDermid A, Moreno M and Stanimirovic D: Interactions of EGFR and caveolin-1 in human glioblastoma cells: evidence that tyrosine phosphorylation regulates EGFR association with caveolae. Oncogene 23: 6967-6979, 2004.

29. Couet J, Sargiacomo M and Lisanti MP: Interaction of a receptor tyrosine kinase, EGF-R, with caveolins. Caveolin binding negatively regulates tyrosine and serine/threonine kinase activities. J Biol Chem 272: 30429-30438, 1997.

30. Khan EM, Heidinger JM, Levy M, Lisanti MP, Ravid T and Goldkorn T: Epidermal growth factor receptor exposed to oxidative stress undergoes Src- and caveolin-1-dependent perinuclear trafficking. J Biol Chem 281: 14486-14493, 2006.

31. Dittmann K, Mayer C, Kehlbach R and Rodemann HP: Radiationinduced caveolin-1 associated EGFR internalization is linked with nuclear EGFR transport and activation of DNA-PK. Mol Cancer 7: 69, 2008.
32. Du ZM, Hu CF, Shao Q, Huang MY, Kou CW, Zhu XF, Zeng YX and Shao JY: Upregulation of caveolin-1 and CD147 expression in nasopharyngeal carcinoma enhanced tumor cell migration and correlated with poor prognosis of the patients. Int J Cancer 125: $1832-1841,2009$

33. Kato K, Hida Y, Miyamoto M, Hashida H, Shinohara T, Itoh T, Okushiba S, Kondo S and Katoh H: Overexpression of caveolin-1 in esophageal squamous cell carcinoma correlates with lymph node metastasis and pathologic stage. Cancer 94: 929-933, 2002.

34. Satoh T, Yang G, Egawa S, Addai J, Frolov A, Kuwao S, Timme TL, Baba S and Thompson TC: Caveolin-1 expression is a predictor of recurrence-free survival in pT2N0 prostate carcinoma diagnosed in Japanese patients. Cancer 97: 1225-1233, 2003.

35. Campbell L, Gumbleton M and Griffiths DF: Caveolin-1 overexpression predicts poor disease-free survival of patients with clinically confined renal cell carcinoma. Br J Cancer 89: 1909-1913, 2003.

36. Forget MA, Desrosiers RR, Del M, Moumdjian R, Shedid D, Berthelet $\mathrm{F}$ and Beliveau R: The expression of rho proteins decreases with human brain tumor progression: potential tumor markers. Clin Exp Metastasis 19: 9-15, 2002.

37. Ho CC, Kuo SH, Huang PH, Huang HY, Yang CH and Yang PC: Caveolin-1 expression is significantly associated with drug resistance and poor prognosis in advanced non-small cell lung cancer patients treated with gemcitabine-based chemotherapy. Lung Cancer 59: 105-110, 2008.

38. Lavie Y, Fiucci G and Liscovitch M: Upregulation of caveolin in multidrug resistant cancer cells: functional implications. Adv Drug Deliv Rev 49: 317-323, 2001.

39. Fiucci G, Ravid D, Reich R and Liscovitch M: Caveolin-1 inhibits anchorage-independent growth, anoikis and invasiveness in MCF-7 human breast cancer cells. Oncogene 21: 2365-2375, 2002.

40. Lee SW, Reimer CL, Oh P, Campbell DB and Schnitzer JE: Tumor cell growth inhibition by caveolin re-expression in human breast cancer cells. Oncogene 16: 1391-1397, 1998.

41. Zhang H, Su L, Muller S, Tighiouart M, Xu Z, Zhang X, Shin HJ, Hunt J, Sun SY, Shin DM and Chen ZG: Restoration of caveolin-1 expression suppresses growth and metastasis of head and neck squamous cell carcinoma. Br J Cancer 99: 1684-1694, 2008.

42. Williams TM and Lisanti MP: Caveolin-1 in oncogenic transformation, cancer, and metastasis. Am J Physiol Cell Physiol 288: C494-C506, 2005.

43. Mandal M, Myers JN, Lippman SM, Johnson FM, Williams MD, Rayala S, Ohshiro K, Rosenthal DI, Weber RS, Gallick GE and El-Naggar AK: Epithelial to mesenchymal transition in head and neck squamous carcinoma: association of Src activation with E-cadherin down-regulation, vimentin expression, and aggressive tumor features. Cancer 112: 2088-2100, 2008.

44. Bailey KM and Liu J: Caveolin-1 up-regulation during epithelial to mesenchymal transition is mediated by focal adhesion kinase. J Biol Chem 283: 13714-13724, 2008. 